\title{
Neumonía recurrente como manifestación de infección por Nocardia
}

\author{
Miguel Ángel Martínez Sáncheza, Juan Carlos Segura Luque ${ }^{b}$, \\ Arancha Albal Garcíaa, Santiago Gómez Ramíreza , Francisco Javier Polo Romeroc, \\ Julio Manuel Moreno Salcedoc, Jose Luis Beato Pérez ${ }^{c}$
}

\begin{abstract}
${ }^{a}$ Residente de Medicina Familiar y Comunitaria. Unidad Docente de Albacete-Hellín

b Servicio de Medicina Interna. Complejo Hospitalario Universitario de Albacete.

c Servicio de Medicina Interna. Hospital de Hellín.

Correspondencia:

Santiago Gómez Ramírez.

Hospital de Hellín,

C/ Juan Ramón Jiménez S/N, Hellín (Albacete).

e-mail: santiresi@hotmail.com
\end{abstract}

Recibido el 17 de junio de 2007.

Aceptado para su publicación el 11 de enero de 2008.

\begin{abstract}
RESUMEN
La nocardiosis es una enfermedad invasiva producida por especies del género Nocardia, bien a través de la inhalación o la inoculación cutánea. Se presentan dos casos de neumonía por Nocardia en pacientes inmunodeprimidos.

Palabras clave. Nocardia, neumonía.
\end{abstract}

\section{ABSTRACT}

Recurrent pneumonia as a manifestation of Norcardia infection.

Nocardiosis is an invasive disease caused by the Norcardia species, either through inhalation or cutaneous inoculation. We report two cases of pneumonia caused by Norcadia in immunodepressed patients.

Key Words. Nocardia, pneumonia.

\section{INTRODUCCIÓN}

La nocardiosis es una enfermedad invasiva producida por especies del género Nocardia, bien a través de la inhalación o la inoculación cutánea. Es un ejemplo de infección oportunista y, al no existir ningún dato clínico ni radiológico distintivo y ser el cultivo lento y dificultoso, su diagnóstico es difícil. Se exponen dos casos de neumonía por Nocardia en pacientes inmunodeprimidos.

\section{OBSERVACIONES CLÍNICAS}

Caso 1. Se trata de un varón de 30 años, diagnosticado de infección por el virus de la inmunodeficiencia humana (VIH) y en tratamiento antirretroviral. Tres meses antes de su ingreso actual presentó una neumonía comunitaria sin germen filiado, la cual fue tratada con cefalosporinas y quinolonas. Ingresó por un cuadro consuntivo, fiebre y expectoración hemoptoica. En la radiografía de tórax destacaba una condensación basal izquierda sin cavitación ni derrame pleural. Se aisló en esputo, boncoaspirado (BAS) y lavado broncoalveolar (BAL) Nocardia spp.

Caso 2. En esta ocasión se trata de un varón de 74 años con antecedentes de adenocacinonma de próstata, diabetes y enfermedad pulmonar obstructiva crónica (EPOC) corticodependiente. El paciente había sido ingresado previamente por neumonía comunitaria basal derecha tratada con quinolonas y de etiología no filiada. Reingresó por deterioro clínico significativo, precisando intubación orofaríngea (IOT) y ventilación mecánica (VM). En la radiografía de tórax presentaba condensación basal y derrame pleural derecho. Se aislaró en BAS y cepillado bronquial Nocardia spp. 


\section{DISCUSIÓN}

La especie Nocardia está formada por bacterias aerobias con filamentos gram-positivos y parcialmente ácido alcohol resistentes (AAR). Las infecciones en humanos son fundamentalmente causadas por Nocardia asteroide y precisan de un deterioro de las defensas pulmonares locales o una inmunosupresión sistémica, particularmente mediada por células, para su desarrollo. La forma más común de presentación de la nocardiosis pulmonar es la de una infección su- purativa pulmonar subaguda o crónica que a menudo se confunda inicialmente con una tuberculosis o un absceso pulmonar. Presenta tendencia pronunciada a pasar por fases espontáneas de remisiones y exacerbaciones con frecuentes recidivas de la infección tras breves tratamientos. La combinación de neumonía recurrente en pacientes con una inmunodepresión natural o adquirida es muy sugerente de nocardiosis pulmonar, por lo que facilita el inicio del un tratamiento adecuado y prolongado.

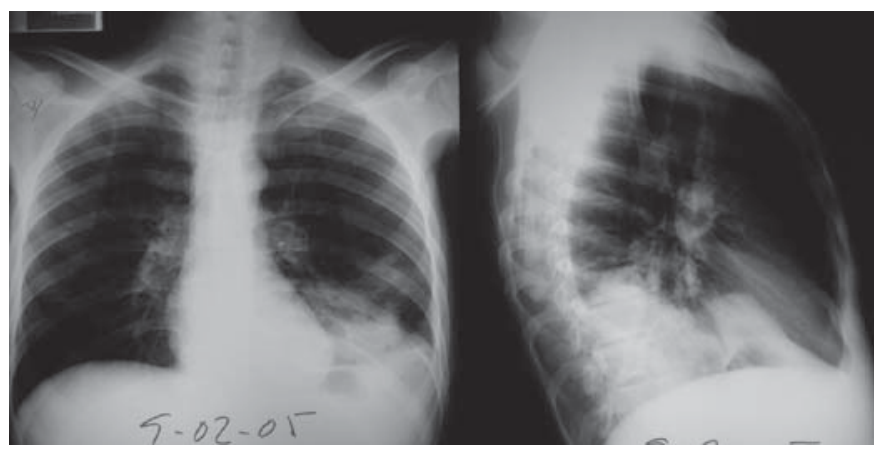

Figura 1. Caso 1: condensación basal izquierda en radiografía de tórax.

\section{BIBLIOGRAFÍA}

1. Wallace RJ, Brown BA, Brown JM, McNeill M. Taxonomy of Nocardia species. Clini Infect dis 1994; 18:476-7.

2. Sorrel TC, Iredell JR, Mitchell DH. Nocardia species. En Mandell GL, Bennett JE, Dolin R, editores. Principles and
Practice of Infectious Diseases. $5 .^{\text {a }}$ ed. Filadelfia: Churchill Livingstone, 2000. p. 2637-45.

3. Lumbreras Bermejo C, Martínez Laceras B. Nocardiosis. Medicine 2002; 8(67); 3573-3578.

4. Pintado V. Nocardial infection in patients infected with the human inmunodeficiency virus. Clin Microbiolog Infect 2003; 9:716-720. 